\title{
A TRAJETÓRIA DA ELABORAÇÃO DE UM PRODUTO EDUCACIONAL COMO ESTRATÉGIA DE PREVENÇÃO DO SUICÍDIO E PROMOÇÃO DE SAÚDE MENTAL NO AMBIENTE ESCOLAR
}

\author{
THE DEVELOPMENT OF AN EDUCATIONAL PRODUCT AS A STRATEGY \\ FOR SUICIDE PREVENTION AND MENTAL HEALTH PROMOTION IN THE \\ SCHOOL ENVIRONMENT
}

\author{
Aneliana da Silva Prado ${ }^{1}$ \\ Leandro Rafael Pinto ${ }^{2}$
}

\begin{abstract}
Resumo: Este artigo apresenta o processo de redação de um produto educacional, tipo e-book, desenvolvido em uma pesquisa de mestrado profissional - área de ensino, que objetivou identificar a percepção e necessidades de formação dos profissionais da educação sobre a prevenção do suicídio para desenvolver um material educativo. As taxas de suicídio dos jovens brasileiros e as situações relacionadas ao comportamento suicida observadas no campo da psicologia educacional motivaram sua escrita. $\mathrm{O}$ material oferece informações sobre prevenção e manejo de situações de risco de suicídio no ambiente escolar. Ele foi desenvolvido com base na perspectiva biopsicossocial e na abordagem multidisciplinar do comportamento suicida. Utilizou-se a metodologia qualitativa e quantitativa e o método de análise de conteúdo para apreciação dos dados. Espera-se referenciar cientificamente os trabalhadores escolares em sua atuação, ampliar e aprimorar as iniciativas de promoção da saúde mental e prevenção do suicídio no contexto educacional, e inspirar pesquisas brasileiras neste âmbito.
\end{abstract}

Palavras-chave: Produto educacional; Prevenção do suicídio; Educação profissional e tecnológica; Saúde mental na escola.

\begin{abstract}
This article presents the writing process of an educational product, e-book type, developed in a professional master's research in the area of education, which aimed to identify the perception and training needs of education professionals about suicide prevention in order to develop an educational material. The suicide rates among Brazilian youth and the situations related to suicidal behavior observed in the field of educational psychology motivated its writing. The material offers information about prevention and management of suicide risk situations in the school environment. It was developed from the biopsychosocial perspective and multidisciplinary approach to suicidal behavior. The qualitative and quantitative methodology and the content analysis method were used to analyze the data. It is expected to scientifically reference school workers in their performance, to expand and improve the initiatives of mental health promotion and suicide prevention in the educational context, and to inspire Brazilian research in this field.
\end{abstract}

Keywords: Educational product; Suicide prevention; Professional and technological education; Mental health at school.

\footnotetext{
${ }^{1}$ Doutoranda do Programa de Pós-graduação em Psicologia (PPGPSI) da Universidade Federal do Paraná (UFPR). Mestra em Educação Profissional e Tecnológica pelo Instituto Federal do Paraná (IFPR). Psicóloga no IFPR - Campus Curitiba. Curitiba, Paraná, Brasil. E-mail: anelianaprado@ gmail.com

${ }^{2}$ Doutor e Mestre em Geografia pela Universidade Federal do Paraná (UFPR). Bacharel e Licenciado em Geografia pela UFPR. Docente do Programa de Pós-Graduação em Educação Profissional e Tecnológica (ProfEPT) no Instituto Federal do Paraná (IFPR). Professor EBTT no IFPR - Campus Curitiba. Diretor de Pós-Graduação do IFPR. Curitiba, Paraná, Brasil. E-mail: leandro.rafael@ifpr.edu.br
} 


\section{Introdução}

Os dados disponíveis sobre a mortalidade por suicídio no Brasil e no mundo demonstram a necessidade de criar e ampliar as práticas de prevenção e promoção da saúde mental na população em geral e, em especial, das populações consideradas de risco - dentre as quais se destaca a população jovem (BRASIL, 2017b; HAWTON; SAUNDERS; O'CONNOR, 2012; WORLD HEALTH ORGANIZATION, 2014). O suicídio e suas tentativas são a segunda causa de internações em jovens de 10 a 19 anos do sexo feminino na rede do Sistema Único de Saúde (SUS) (BENINCASA; REZENDE, 2006). Na população brasileira de 15 a 29 anos de idade, o suicídio representa a quarta principal causa de morte externa (BRASIL, 2017a). Na população geral, os dados epidemiológicos mais recentes, publicados pelo Ministério da Saúde (MS), apontam que, de 2011 a 2015, a taxa de suicídio variou de 5,3 em 2011 a 5,7 em 2015 (BRASIL, 2017b).

Em 2019, foi publicada a Lei $\mathrm{n}^{\mathrm{o}} 13.819$, que institui a Política Nacional de Prevenção da Automutilação e do Suicídio no Brasil (BRASIL, 2019). Em razão de seu caráter recente, sua regulamentação ainda necessita ser estruturada. Segundo esta Lei, os estabelecimentos de ensino públicos e privados deverão notificar compulsoriamente os casos de violência autoprovocada que englobam o suicídio consumado, a tentativa de suicídio e a automutilação com ou sem ideação suicida. Diante disso, em acordo com o que já vinha sendo apontado pelos órgãos de saúde e pesquisadores da área, reforçou-se a necessidade de ampliação dos estudos sobre o tema (BOTEGA, 2015; GARCIA, 2018; MACHADO; LEITE; BANDO, 2014; SCAVACINI, 2011, 2018; WAISELFISZ, 2014).

A percepção sobre a escola como espaço gerador de sofrimento ultrapassou a esfera do sofrimento no trabalho dos profissionais da educação e a discussão foi ampliada para o corpo estudantil. A contradição representada por um ambiente que deveria promover crescimento e autonomia para o aluno, mas que também é o fator gerador de seu sofrimento pode ser pode ser facilmente identificada em diversos casos. Sabe-se que a questão sucesso versus fracasso escolar está também relacionada às condições e ao arranjo educacional existente, não estando apenas sob a responsabilidade do "esforço" do aluno. Nesse contexto, observa-se que as formas de compreensão do mundo, embasadas ou não em concepções teóricas, interferem na forma como esse aluno é visto e ensinado.

A ideia de competição trazida do mercado de trabalho promove sofrimento, individualização e, comumente, a "patologização" (e até medicalização) do desempenho abaixo do esperado - o que pode contribuir para que a escola seja um local de produção 
de senso de incapacidade/incompetência do aluno. Um exemplo disso é o estudo de Teixeira (2007), no qual adolescentes escolares apontaram a escola mais como um ambiente desfavorável ao crescimento de uma pessoa do que relacionado a uma dimensão que favoreça a vida e os sentimentos de amor próprio e esperança.

Diante deste preocupante cenário e da necessidade observada no campo de trabalho da autora (psicóloga escolar de uma instituição federal de educação, ciência e tecnologia de grande porte), sua pesquisa de mestrado previu a elaboração de um produto educacional que versasse sobre a prevenção do suicídio e o manejo de situações de risco de suicídio no ambiente escolar. Esta pesquisa foi realizada no âmbito do Programa de Mestrado Profissional em Educação Profissional e Tecnológica (ProfEPT) - Área de Ensino, que tem como requisito obrigatório para a conclusão a elaboração de um produto educacional, além da dissertação (CAPES, 2016).

O produto educacional é uma produção técnica de realização obrigatória no âmbito dos programas de Mestrado Profissional, podendo ser de um dos seguintes tipos: mídias educacionais; protótipos educacionais e materiais para atividades experimentais; propostas de ensino; material textual; materiais interativos; atividades de extensão e desenvolvimento de aplicativos (CAPES, 2016). A produção deste material deve ser dirigida a públicos específicos e compreender processos de formação em ambientes de ensino formal e não formal. Além disso, o produto deve ser registrado preferencialmente em formato digital (PDF ou outro) e ter um link de acesso disponibilizado no sítio eletrônico da instituição (CAPES, 2016). No trabalho em questão, o produto educacional desenvolvido foi um material textual, no formato e-book, disponibilizado em arquivo PDF.

Assim, embora já existissem cartilhas educativas relacionadas à temática do suicídio, foi observado que, comumente, elas se inseriam em um paradigma biomédico e relacionavam o suicídio prevalentemente a questões de doença mental. A única cartilha especificamente voltada a profissionais da educação elaborada pela Organização Mundial de Saúde (OMS, 2000), trata-se de uma tradução para a língua portuguesa e, até o momento em que a pesquisa foi iniciada, não havia sido encontrado um material educativo voltado para a área educacional que tivesse sido desenvolvido no contexto brasileiro, considerando suas especificidades. Destarte, propôs-se a elaboração de um material que atendesse às demandas locais e que refletisse o modo de organização da escola e do sistema de saúde brasileiro. Ademais, que tivesse uma compreensão do suicídio como um processo comportamental desenvolvido pelo indivíduo por meio de 
suas interações com seu ambiente, sua cultura e sua história ontogenética, sob uma perspectiva biopsicossocial.

O estudo do qual derivou o produto tinha por objetivo identificar a percepção dos profissionais que atuam na área pedagógica dos campi do IFPR sobre a temática de prevenção do suicídio e suas necessidades de formação neste assunto, com vistas a desenvolver um material educativo sobre o tema. Ele se caracterizou como uma pesquisa exploratória de método misto - qualitativo e quantitativo (CRESWELL, 2007) - e análise de conteúdo baseada em Bardin (2016). As técnicas utilizadas foram questionários semiestruturados para as etapas de levantamento de dados e de avaliação do produto educacional. A pesquisa foi aprovada pelo Comitê de Ética em Pesquisa (CEP) do IFPR - CAAE no 82764618.4.0000.8156.

O contexto no qual este estudo se inseriu é o da Educação Profissional e Tecnológica (EPT), em que o trabalho é compreendido como princípio educativo, em uma visão omnilateral de homem (NOSELLA, 2007) e unitária e politécnica em relação à educação (RAMOS, 2008; SAVIANI, 2007) ou tecnológica (NOSELLA, 2007), voltada para formação integral e crítica. Nesta perspectiva, propõe-se (pelo menos como pressuposto) a (re)união entre o trabalho e a educação (escola) e entre o trabalho intelectual e o trabalho manual no processo de formação. Preconiza-se a unidade teóricoprática, de forma a romper a dualidade saber-fazer (voltada aos trabalhadores) versus saber-pensar (voltada à elite) em vigor na forma de organização da educação brasileira (SAVIANI, 2007).

\section{Contexto da Educação Profissional e Tecnológica}

A Educação Profissional e Tecnológica (EPT) é uma modalidade educacional prevista na Lei de Diretrizes e Bases da Educação Nacional (LDB) com a finalidade primordial de preparar o estudante "para o exercício de profissões", para que ele possa se inserir e atuar no mundo do trabalho e na vida em sociedade. A EPT compreende cursos de qualificação, habilitação técnica e tecnológica, e de pós-graduação, organizados de forma a propiciar o aproveitamento contínuo e articulado dos estudos.

A EPT surgiu em um contexto em que os requisitos de formação do trabalhador ficaram cada vez mais exigentes, ao mesmo tempo em que, contraditoriamente, o trabalhador continuava sem acesso a um ensino básico adequado. Observa-se uma formação profissional dicotômica: com uma formação geral (de natureza propedêutica) 
de um lado e a formação específica (de natureza técnica) de outro. Nessa lógica, a EPT apresentou-se como uma proposta alternativa de educação profissional no sentido de propor a integração do par teoria-prática (CARVALHO; LACERDA, 2010).

Entretanto, como expõe Ramos (2008), é reconhecido que a proposta de EPT atualmente em vigor, em especial com relação ao ensino médio na modalidade em que é integrado ao ensino técnico, ofertada principalmente por meio da Rede Federal de Educação Profissional, Científica e Tecnológica, ainda não alcança a totalidade desses objetivos. Contudo, isso não deve motivar a invalidação da proposta. Ao contrário, é reconhecido que ela se apresenta como modelo de travessia para o alcance desses objetivos ao propor a integração interdisciplinar da educação básica com a educação profissional.

No Brasil, atualmente, os Institutos Federais representam importante papel na oferta da EPT, integrando diferentes níveis e modalidades da Educação às dimensões do trabalho, da ciência e da tecnologia. Os Institutos Federais de Educação, Ciência e Tecnologia, doravante denominados Institutos Federais ou referenciados pela sigla IFs, foram criados pela Lei $\mathrm{n}^{\mathrm{o}} 11.892$, de 29 de dezembro de 2008. Juntamente com a Universidade Tecnológica Federal do Paraná (UTFPR), os Centros Federais de Educação Tecnológica Celso Suckow da Fonseca (CEFET-RJ) e de Minas Gerais (CEFET-MG), as Escolas Técnicas Vinculadas às Universidades Federais e o Colégio Pedro II, compõem a Rede Federal de Educação Profissional, Científica e Tecnológica (RFEPCT), vinculada ao Ministério da Educação (MEC).

Conforme sua lei de criação, os Institutos Federais são "instituições de educação superior, básica e profissional, pluricurriculares e multicampi, especializados na oferta de educação profissional e tecnológica nas diferentes modalidades de ensino, com base na conjugação de conhecimentos técnicos e tecnológicos com as suas práticas pedagógicas" (BRASIL, 2008). Dentre os seus objetivos, destaca-se o de "ministrar educação profissional técnica de nível médio, prioritariamente na forma de cursos integrados, para os concluintes do ensino fundamental e para o público da educação de jovens e adultos" (Art. 7, Alínea I). Assim, neste âmbito deve ser garantido, em cada exercício, o mínimo de 50\% (cinquenta por cento) das vagas da Instituição (Art. 8).

Nos objetivos dos IFs reside o pressuposto de formação dos estudantes para o mundo do trabalho, não apenas para o mercado de trabalho, o que implica uma proposta de formação crítica. Dessa forma, a EPT é pensada como um projeto contra-hegemônico, no sentido de visar à formação de sujeitos autônomos e protagonistas, não apenas mão de 
obra qualificada para produção de renda e empregabilidade. Além disso, ao se considerar a importância do desenvolvimento socioeconômico local e regional, a ampliação de Rede Federal de Ensino por meio dos IFs não se restringiu aos grandes centros urbanos; ao contrário, promoveu a interiorização da EPT com a abertura de novos campi no interior dos estados brasileiros.

É nesse contexto educacional, no qual se compreende o processo educativo como parte da formação humana do educando e o ambiente escolar como lugar de potencialidade para o desenvolvimento integral do estudante, que este trabalho propõe sua contribuição. Para tanto, as ações de prevenção do suicídio são compreendidas em seu sentido mais amplo e universal, principalmente no que se refere à diminuição do estigma sobre o tema, no apoio adequado para os alunos com ideação, tentativa ou aqueles sobreviventes enlutados por suicídio ${ }^{3}$.

\section{Metodologia de levantamento e análise de dados}

O Instituto Federal do Paraná (IFPR) foi a instituição escolhida para ser o lócus da pesquisa em razão de ser o local de trabalho da pesquisadora, que, ao realizar algumas palestras de prevenção do suicídio nas unidades da instituição, percebeu a necessidade de ampliar a discussão sobre o tema. Além disso, o fato de ser servidora no IFPR permitiria melhor acesso ao público-alvo da pesquisa. A capilaridade geográfica da instituição no estado do Paraná (20 campi e 6 campi avançados) também foi levada em consideração. Outro fator relevante na escolha foi que a cidade de Curitiba apresentava um dos maiores índices de suicídio entre as capitais brasileiras (WAISELFISZ, 2014), sendo o Paraná um dos estados com maiores taxas de suicídio no Brasil (ROSA et al., 2017).

O IFPR é uma instituição pública federal de ensino vinculada ao Ministério da Educação (MEC) por meio da Secretaria de Educação Profissional e Tecnológica (SETEC). É voltada para a educação superior, básica e profissional, especializada na oferta gratuita de educação profissional e tecnológica nas diferentes modalidades e níveis de ensino. A instituição foi criada em dezembro de 2008 por meio da Lei $\mathrm{n}^{\circ} 11.892$, que instituiu a RFEPCT e os 38 Institutos Federais existentes no país. Atualmente, segundo a Plataforma Nilo Peçanha $(2020)^{4}$, a instituição tem mais de 30 (trinta) mil estudantes

\footnotetext{
${ }^{3}$ Expressão utilizada para identificar qualquer pessoa que teve a vida afetada ou mudada em razão da morte por suicídio. Na literatura, encontra-se também a expressão "sobrevivente do suicídio" (SCAVACINI, 2018).

${ }^{4}$ Disponível em: www.plataformanilopecanha.mec.gov.br. Acesso em: 11 de dez. 2020.
} 
matriculados nos cursos presenciais e a distância. São 349 (trezentos e quarenta e nove) cursos, divididos entre Formação Inicial e Continuada (FIC), Técnicos (Integrados e Subsequentes), Graduações e Pós-Graduações. O foco de atuação dos Institutos Federais é o Ensino Médio (EM), em especial de forma integrada à educação profissional, em que os alunos têm, em média, 14 a 17 anos.

Os profissionais que atuam na área pedagógica e/ou de assistência estudantil dos campi do IFPR foram selecionados como público-alvo da pesquisa em razão de estarem em contato mais frequente com as questões ligadas a queixas relativas aos alunos, que podem indicar fatores de risco para o suicídio (SOUSA, 2017; PEREIRA et al., 2018; (CARDOSO; CECCONELLO, 2019). Desse modo, na organização do trabalho no campus, são os profissionais que atuam nesses setores aqueles que comumente recebem dos pais, dos alunos ou de seus colegas, dos professores ou de outros profissionais da escola, a indicação de que o aluno apresenta algum "problema", de aprendizagem, de comportamento, de saúde, dentre outros. Nesse sentido, acabam sendo, na maioria das vezes, o elo entre a escola e os serviços de saúde nos quais o aluno é atendido ou mesmo entre a escola e o Conselho Tutelar, por exemplo. Diante disso, considerou-se que esses profissionais seriam os mais indicados para apontar as ações realizadas, bem como aquelas necessárias no âmbito da prevenção do comportamento suicida na escola.

Para tanto, um questionário com perguntas de múltipla escolha e perguntas abertas foi produzido pelos pesquisadores para identificar a percepção dos profissionais sobre a prevenção do suicídio nos campi do IFPR, bem como a eventual necessidade de (in)formação dos profissionais sobre o tema. Foram selecionados os servidores dos cargos de Assistente de Alunos, Assistente Social, Pedagogo, Psicólogo e Técnico em Assuntos Educacionais para responder ao questionário eletrônico via Google Forms, enviado por e-mail, processo que teria uma duração de 15 a 30 minutos. Para isso, os servidores deveriam, obrigatoriamente, assinalar que concordavam com o Termo de Consentimento Livre e Esclarecido (TCLE) enviado anexo ao convite para participar da pesquisa. Neste e-mail de convite, havia uma breve explicação sobre a natureza da pesquisa, seu objetivo, o tempo previsto para resposta e o contato dos pesquisadores. O TCLE continha o carimbo de assinatura de aprovação da pesquisa pelo Comitê de Ética em Pesquisa (CEP).

Os endereços eletrônicos de 127 (cento e vinte e sete) servidores foram retirados da página eletrônica dos campi do IFPR e da planilha eletrônica de contatos dos servidores do IFPR, alimentada pela Secretaria do Gabinete do Reitor e compartilhada com os servidores do Instituto. Após um período de 18 (dezoito) dias, foram obtidas 49 
(quarenta e nove) respostas que compuseram a amostra $(n=49)$. Houve representatividade de todas as unidades do Instituto, algumas com mais de uma participação.

A escolha da utilização do questionário semiestruturado como instrumento de pesquisa se deu em razão da quantidade e da localização geográfica dos participantes. Foram levados em consideração, especialmente, o custo da técnica e a disponibilidade de tempo dos pesquisadores para a coleta de dados. O questionário é um conjunto de perguntas articuladas para levantar informações fornecidas pelos participantes com o objetivo de conhecer suas opiniões sobre o assunto estudado (SEVERINO, 2007).

Nesse sentido, os dados coletados no questionário tinham a finalidade de fornecer subsídios para a construção de um produto educacional que viesse ao encontro das necessidades dos profissionais sobre o comportamento suicida na escola, principalmente a prevenção, por meio de proposta que levasse em consideração sua participação. Assim, as variáveis relevantes e antes desconhecidas sobre o fenômeno, que são necessárias à construção de uma intervenção, puderam ser identificadas (CRESWELL, 2007). O corpus obtido por meio do questionário foi analisado pelo método da Análise de Conteúdo proposto por Bardin (2016). Segundo a autora, a análise de conteúdo é um

conjunto de técnicas de análise das comunicações visando obter por
procedimentos sistemáticos e objetivos de descrição do conteúdo das
mensagens indicadores (quantitativos ou não) que permitam a inferência de
conhecimentos relativos às condições de produção/recepção (variáveis
inferidas) dessas mensagens (BARDIN, 2016, p. 48).

A partir do trabalho com unidades linguísticas superiores à frase (enunciados), ela visa ao "conhecimento de variáveis de ordem psicológica, sociológica, histórica etc., por meio de um mecanismo de dedução com base em indicadores reconstruídos a partir de uma amostra de mensagens particulares” (BARDIN, 2016, p. 50). A análise de conteúdo pressupõe que a passagem dos dados brutos para dados organizados, denominada "categorização", não instaura desvios (por excesso ou por renúncia) no material, mas permite o conhecimento de índices invisíveis no mesmo nível dos dados brutos (BARDIN, 2016).

Em se tratando da análise de respostas a questões abertas, elas são frequentemente analisadas tendo o tema como base. Para a autora, realizar uma análise temática consiste em “descobrir os 'núcleos de sentido' que compõem a comunicação e cuja presença, ou frequência de aparição, podem significar alguma coisa para o objetivo analítico escolhido" (BARDIN, 2016, p. 135). Assim, como unidade de registro, o tema 
corresponde a uma regra de recorte que não é fornecida a priori, mas é dada no próprio corpus construído. Portanto, a análise feita para a construção dos temas compreende a escolha das unidades (o recorte), a classificação e a agregação para a realização das categorias.

\section{0 produto educacional e sua trajetória de elaboração}

Um dos objetivos específicos da pesquisa foi produzir um material educativo sobre prevenção do suicídio no ambiente escolar, voltado aos profissionais da área educacional da RFEPCT. Para tanto, conforme relatado, foi necessário identificar a percepção sobre a temática de prevenção do suicídio e as necessidades de formação neste assunto dos profissionais que atuam na área pedagógica dos campi de um instituto federal de educação.

A escolha do tipo de produto educacional $e$-book se deu em razão de este ser um material de baixo custo de produção e com possibilidade de inserção de material extra em formato de hiperlinks, por exemplo. Além disso, é de acesso fácil, irrestrito e permanente para o público-alvo, tendo sido um dos tipos de materiais identificados no levantamento de dados junto aos participantes como útil ao objetivo proposto pela pesquisa.

Para a elaboração do material, além do levantamento de dados com os servidores, foram realizadas sistematização e síntese das informações encontradas na revisão bibliográfica feita sobre o tema de prevenção do suicídio, conforme apresentado no Fluxograma 1. Essas informações foram organizadas no formato de texto verbal, por meio de um editor de texto, utilizando uma linguagem mais informativa, direta, menos acadêmica e que fosse contingente aos aspectos indicados pelos participantes da pesquisa por meio de questionário semiestruturado. Posteriormente, o material foi enviado para um designer gráfico para realização da diagramação no formato de cartilha digital, para inserção das informações visuais. 
Fluxograma 1: Trajetória de elaboração da pesquisa e do produto educacional

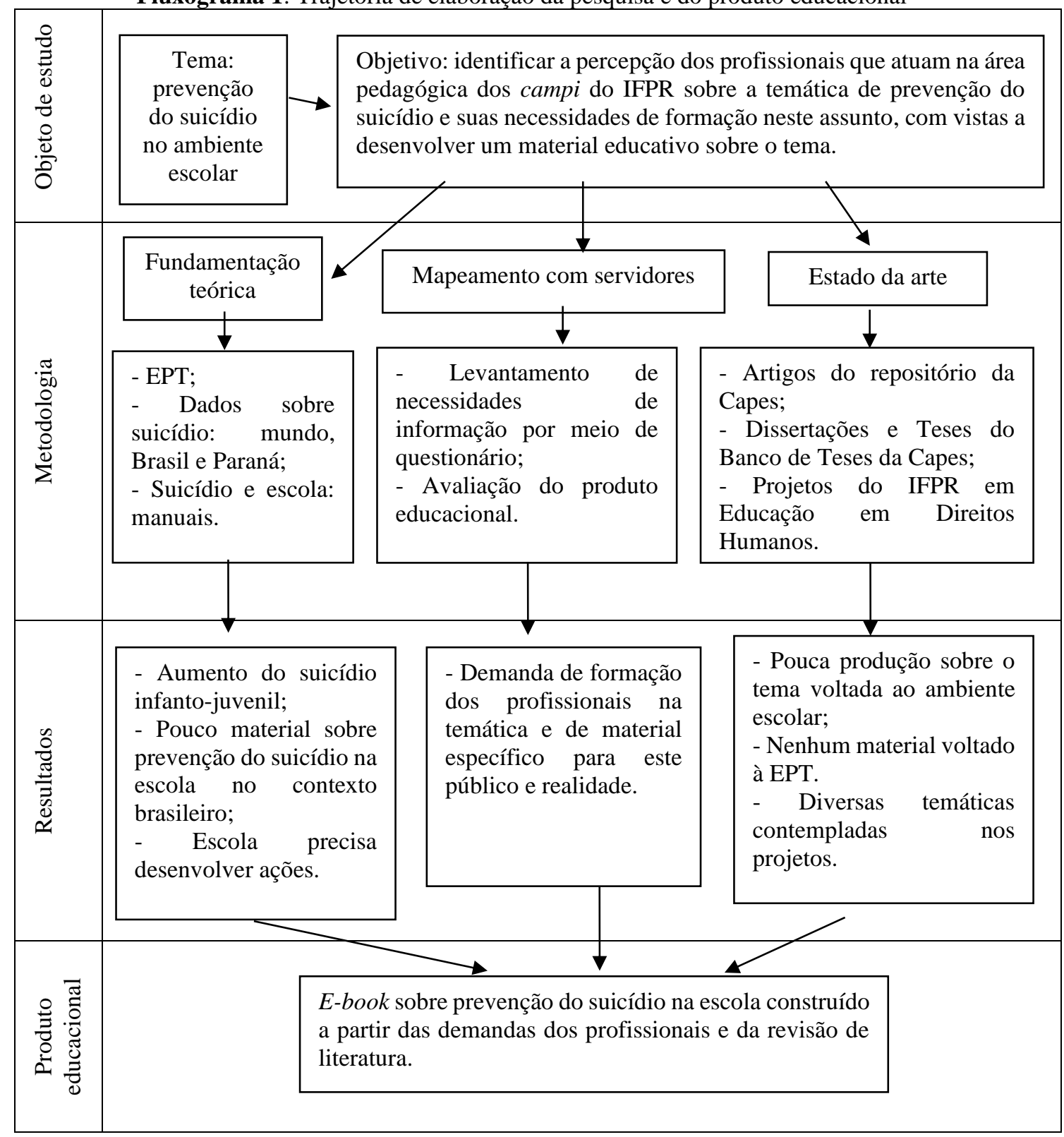

Fonte: Prado (2019a)

Para fins de aplicação do produto educacional, realizou-se no IFPR - Campus Curitiba uma avaliação da usabilidade e conteúdo do produto, por meio da elaboração de uma ação de formação em prevenção do suicídio para os profissionais da Seção Pedagógica, de Assuntos Estudantis e da Direção de Ensino. A aplicação foi realizada por um profissional de enfermagem que atua no "Espaço Saúde" do campus (espaço em que dois servidores técnicos administrativos da área de enfermagem realizam triagem e atendimento em saúde de alunos e servidores da unidade).

O profissional optou pelo gênero "palestra" para realizar a aplicação do produto. O objetivo era que ela fosse desenvolvida com base unicamente no material disponibilizado, a fim de que o profissional avaliasse a qualidade e a suficiência do 
material para uma ação deste tipo (o resumo de seu conteúdo pode ser observado na Figura 1). Assim, seria possível indicar ajustes necessários identificados a partir da experiência prática com profissionais que atuam na área pedagógica e também por meio de suas considerações durante a palestra. Esta etapa será melhor descrita no próximo tópico.

Figura 1: Sumário do produto educacional

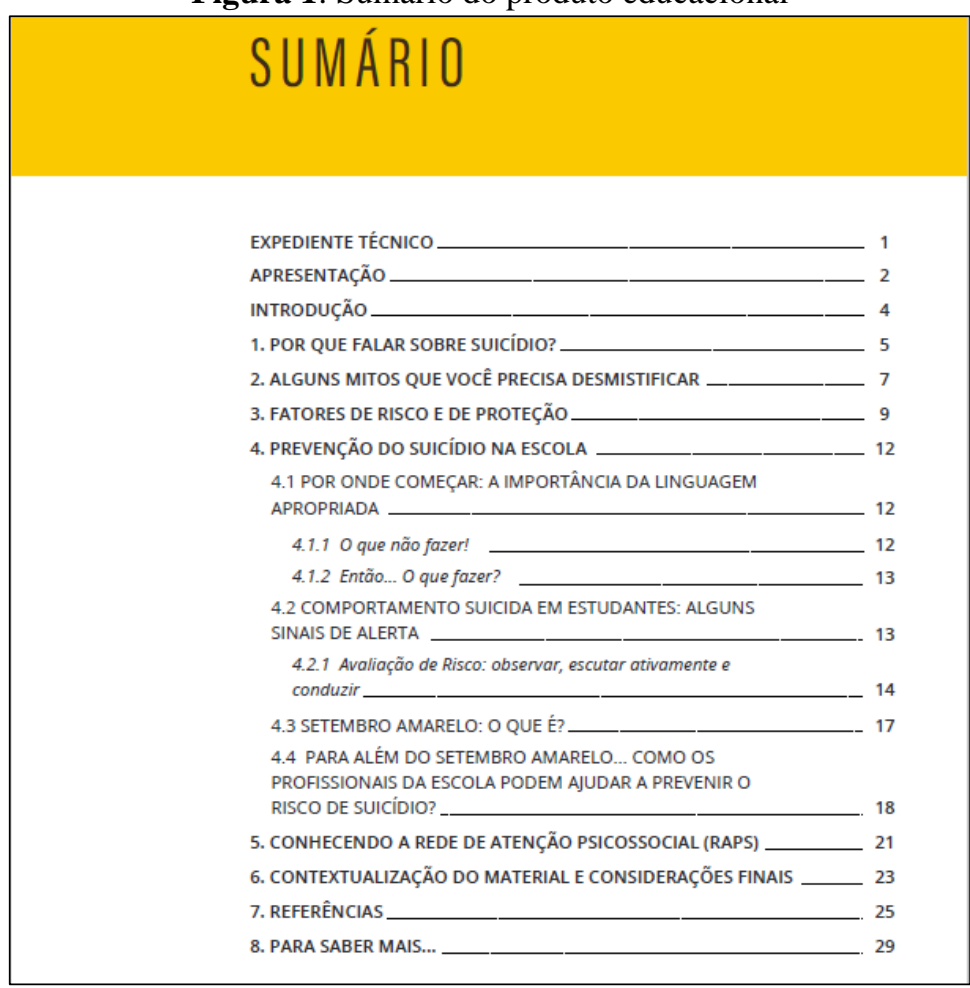

Fonte: Prado (2019b)

Além disso, os 13 (treze) servidores do campus Curitiba que participaram da ação e os 46 (quarenta e seis) profissionais do IFPR que demonstraram interesse no tema na ocasião do levantamento de dados também foram convidados a avaliar o produto por meio de questionário eletrônico, com perguntas fechadas e uma aberta. Assim, do total de 59 (cinquenta e nove) profissionais que receberam o material para avaliação, 20 responderam representando o corpo técnico e docente $(n=20)$. Os cargos de Assistente em Administração, Assistente de Alunos e Docente não contemplados na primeira etapa de levantamento de dados foram incluídos nesta fase. Após essas avaliações, o material sofreu as alterações sugeridas julgadas pertinentes e seguiu para adequações necessárias e finalização. Assim, o produto educacional se tornou parte integrante da dissertação e também foi disponibilizado em link próprio tanto na Plataforma EduCapes quanto no sítio eletrônico da Instituição, para acesso aberto e gratuito. Desde a sua publicação, em 
outubro de 2019, o material possui quase 2 mil visualizações nas plataformas EduCAPES e ResearchGate, e 1.408 downloads da plataforma EduCAPES.

\subsection{Aplicação do produto educacional no Campus}

Para a aplicação do produto educacional, o IFPR - Campus Curitiba foi escolhido por ser a unidade com maior número de alunos presenciais e pela acessibilidade da pesquisadora à unidade. Assim, na tarde do dia 11 de junho de 2019, em uma sala de aula do Campus Curitiba do IFPR, foi realizada uma palestra junto aos profissionais da Seção Pedagógica, da Seção de Assuntos Estudantis e da Direção de Ensino do Campus. Estiveram presentes o profissional de enfermagem que realizou a atividade, a autora deste trabalho como observadora, e 14 (quatorze) servidores do Campus integrantes dos setores mencionados anteriormente. A atividade teve duração de 1 hora e 30 minutos.

Antes dessa ação, foi enviado um Questionário de Atitudes Frente ao Comportamento Suicida, que foi adaptado de Botega et al., (2005) e Magrini (2016) e aplicado novamente após a ação, a fim de observar se haveria alterações. O questionário original é voltado aos profissionais da área de enfermagem, de forma que os itens relacionados a esse contexto foram suprimidos, outros foram adaptados ao contexto escolar e um único item inédito foi acrescentado.

O profissional iniciou a atividade se apresentando, ocasião na qual explicitou ter experiência no atendimento a pessoas que realizaram tentativas de suicídio quando trabalhava em um hospital. Nesse sentido, expôs a importância da formação com respeito ao tema, pois, mesmo no âmbito da saúde, muitas vezes os profissionais não sabem como lidar e tratam o paciente de forma inadequada. Destacou também a relevância de trabalhar a prevenção e a importância do trabalho proposto. Informou que a leitura do produto educacional gerou curiosidade e interesse pelo assunto e que, diante disso, realizou pesquisas à parte, incluindo algumas poucas informações epidemiológicas na apresentação. Desse modo, apresentou a média de recursos públicos utilizados nas situações de tentativa e morte por suicídio no Brasil, como os gastos com internação hospitalar. Apesar disso, explicou que tentou ater-se ao material educativo na organização da formação.

O profissional elaborou slides com base no conteúdo como suporte para a explanação. A apresentação seguiu a mesma ordem dos itens propostos no material e o apresentador relatou alguns exemplos pessoais de sua prática profissional na instituição, 
bem como a relação com sua área de pesquisa, a saber, álcool e drogas. Em relação aos mitos apresentados no material, o profissional relatou a revisão das crenças que tinha antes de lê-lo, realizando, assim, um relato pessoal de aprendizagem. Destacou ainda a importância de pensar na abordagem que leva em consideração a pessoa, e não apenas sua doença ou dificuldade. Por fim, apontou a importância da escola na prevenção do suicídio como parte de uma rede de apoio ao estudante que deve estar em parceria com a rede de saúde e a família.

Ao final, alguns participantes fizeram algumas perguntas sobre a apresentação, principalmente relacionadas à dúvida de falar ou não sobre o suicídio no ambiente escolar, pelo receio do efeito de contágio. Foi, então, explicitado o papel protetivo de abordar o tema divulgando as formas de ajuda e encaminhando para acompanhamento profissional quando necessário. Foi destacada também a relevância de estimular o desenvolvimento dos fatores de proteção no ambiente escolar.

Os presentes e o profissional que conduziu o momento expuseram que o tempo foi pouco para a complexidade do conteúdo e do material, sugerindo, então, outros momentos em que esse tema pudesse ser discutido no grupo, principalmente para que estratégias de promoção à saúde mental pudessem ser desenvolvidas. Foi sugerido ainda por uma das participantes que a apresentação fosse feita junto ao corpo docente da instituição. Depois, foi informado aos participantes que eles também teriam, posteriormente, acesso ao material para avaliação por meio de formulário eletrônico. Solicitou-se, então, ao profissional que preparou a formação que também realizasse uma avaliação descritiva do material, a fim de indicar os ajustes julgados necessários, tendo sido realizada por meio de anotações no material e entregue à pesquisadora.

A Tabela 1 apresenta as respostas do Questionário de Atitudes Frente ao Comportamento Suicida, cujas respostas variaram de 1 (“discordo totalmente") a 5 ("concordo plenamente"), sendo que o número 3 indicava "sem opinião formada/indiferente".

Na primeira aplicação do questionário, foram recebidas 11 (onze) respostas e, na segunda, 8 (oito) respostas. Contudo, somente 5 (cinco) participantes responderam antes e depois da aplicação da ação de capacitação no Campus, assim, apenas seus dados foram analisados para fins da avaliação da usabilidade do material.

Esses participantes foram denominados pelas letras A, B, C, D e E, para que suas identidades fossem preservadas. Nenhum deles tem formação na área de saúde mental e, no que se refere à titulação, a amostra foi composta por três participantes com nível 
superior completo (C, D, E), um participante com mestrado (A) e outro com doutorado (B). Apenas o participante B nunca havia comparecido a ações de capacitação sobre prevenção do suicídio antes desta. Quatro participantes eram do gênero feminino e um, do gênero masculino, sendo que, a fim de preservar suas identidades, não serão identificados a esse respeito.

O Questionário foi organizado em quatro categorias propostas por Botega et al. (2005) para fins de análise, a saber: 1) Capacidade profissional; 2) Direito ao suicídio; 3) Sentimentos em relação à pessoa; 4) Sem categoria específica. De forma geral, a categoria em que mais se observou alterações na soma de itens de todos os participantes foi a de Sentimentos em relação à pessoa. No entanto, como essa categoria contém dois itens a mais que as outras, este dado não é suficiente para indicar destaque. Contudo, apenas nesta categoria ocorreu o fato de dois itens terem sofrido alteração na resposta de todos os participantes em ambas as fases.

Tabela 1: Respostas do Questionário de Atitudes Frente ao Comportamento Suicida

\begin{tabular}{|c|c|c|c|c|c|c|c|}
\hline \multirow[t]{2}{*}{ Categorias } & \multirow[t]{2}{*}{ Itens } & \multirow[t]{2}{*}{ Fase } & \multicolumn{5}{|c|}{ Participantes } \\
\hline & & & $\mathbf{A}$ & B & C & D & $\mathbf{E}$ \\
\hline \multirow{10}{*}{$\begin{array}{l}\text { 1. } \\
\text { Capacidade } \\
\text { profissional }\end{array}$} & \multirow{2}{*}{$\begin{array}{l}\text { Sinto-me capaz de ajudar uma pessoa que } \\
\text { tentou se matar }\end{array}$} & Pré & 3 & 2 & 4 & 3 & 3 \\
\hline & & Pós & 3 & 1 & 5 & 3 & 3 \\
\hline & \multirow{2}{*}{$\begin{array}{l}\text { Sinto-me capaz de perceber quando um } \\
\text { estudante tem risco de se matar }\end{array}$} & Pré & 2 & 3 & 1 & 3 & 2 \\
\hline & & Pós & 1 & 1 & 1 & 3 & 2 \\
\hline & \multirow{2}{*}{$\begin{array}{l}\text { Tenho preparo profissional para lidar com um } \\
\text { estudante com risco de suicídio }\end{array}$} & Pré & 3 & 1 & 1 & 3 & 2 \\
\hline & & Pós & 1 & 1 & 3 & 3 & 4 \\
\hline & \multirow{2}{*}{$\begin{array}{l}\text { Sinto-me inseguro(a) para lidar com estudantes } \\
\text { com risco de suicídio }\end{array}$} & Pré & 3 & 3 & 1 & 3 & 4 \\
\hline & & Pós & 3 & 4 & 5 & 3 & 5 \\
\hline & \multirow{2}{*}{$\begin{array}{l}\text { Eu sei como encaminhar um estudante com } \\
\text { risco de suicídio para a rede de saúde local }\end{array}$} & Pré & 3 & 1 & 1 & 2 & 2 \\
\hline & & Pós & 1 & 3 & 1 & 3 & 3 \\
\hline \multirow{4}{*}{$\begin{array}{l}\text { 2. Direito ao } \\
\text { suicídio }\end{array}$} & \multirow{2}{*}{$\begin{array}{l}\text { Apesar de tudo, penso que, se uma pessoa } \\
\text { deseja se matar, ela tem esse direito }\end{array}$} & Pré & 1 & 1 & 4 & 3 & 3 \\
\hline & & Pós & 3 & 2 & 3 & 3 & 1 \\
\hline & \multirow{2}{*}{$\begin{array}{l}\text { Diante de um suicídio penso: se alguém tivesse } \\
\text { conversado, a pessoa teria encontrado outro } \\
\text { caminho }\end{array}$} & Pré & 3 & 5 & 5 & 3 & 3 \\
\hline & & Pós & 2 & 3 & 4 & 3 & 3 \\
\hline
\end{tabular}




\begin{tabular}{|c|c|c|c|c|c|c|c|}
\hline & \multirow[t]{2}{*}{ A vida é um dom de Deus, e só ele pode tirar } & Pré & 3 & 1 & 1 & 3 & 1 \\
\hline & & Pós & 5 & 1 & 1 & 3 & 3 \\
\hline & \multirow{2}{*}{$\begin{array}{l}\text { Quem tem Deus no coração, não vai tentar se } \\
\text { matar }\end{array}$} & Pré & 3 & 1 & 1 & 1 & 2 \\
\hline & & Pós & 2 & 3 & 1 & 3 & 2 \\
\hline & \multirow[t]{2}{*}{$\begin{array}{l}\text { Quando uma pessoa fala de pôr fim à vida, } \\
\text { tento tirar aquilo da cabeça dela }\end{array}$} & Pré & 4 & 3 & 4 & 3 & 3 \\
\hline & & Pós & 3 & 1 & 4 & 3 & 3 \\
\hline \multirow{14}{*}{$\begin{array}{l}3 . \\
\text { Sentimentos } \\
\text { em relação à } \\
\text { pessoa }\end{array}$} & \multirow{2}{*}{$\begin{array}{l}\text { No fundo, prefiro não me envolver muito com } \\
\text { pessoas que tentaram suicídio, sejam } \\
\text { estudantes ou colegas de trabalho }\end{array}$} & Pré & 1 & 1 & 1 & 1 & 2 \\
\hline & & Pós & 3 & 1 & 1 & 3 & 2 \\
\hline & \multirow[t]{2}{*}{ Quem fica a ameaçar, geralmente não se mata } & Pré & 1 & 1 & 1 & 1 & 2 \\
\hline & & Pós & 3 & 2 & 3 & 3 & 3 \\
\hline & \multirow[t]{2}{*}{$\begin{array}{l}\text { Tenho receio de perguntar sobre ideias de } \\
\text { suicídio e acabar induzindo a pessoa a isso }\end{array}$} & Pré & 2 & 4 & 5 & 3 & 2 \\
\hline & & Pós & 4 & 4 & 1 & 3 & 3 \\
\hline & \multirow{2}{*}{$\begin{array}{l}\text { No fundo, às vezes dá raiva de lidar com } \\
\text { alguém que quer morrer quando tem tanta } \\
\text { gente querendo viver e luta por isso }\end{array}$} & Pré & 1 & 3 & 1 & 1 & 1 \\
\hline & & Pós & 1 & 1 & 1 & 3 & 1 \\
\hline & \multirow{2}{*}{$\begin{array}{l}\text { A gente se sente impotente diante de uma } \\
\text { pessoa que quer se matar }\end{array}$} & Pré & 4 & 4 & 5 & 3 & 3 \\
\hline & & Pós & 3 & 2 & 3 & 3 & 4 \\
\hline & \multirow{2}{*}{$\begin{array}{l}\text { No caso de pessoas que estejam sofrendo muito } \\
\text { devido a uma doença física, acho mais } \\
\text { aceitável a ideia de suicídio }\end{array}$} & Pré & 4 & 2 & 4 & 1 & 4 \\
\hline & & Pós & 3 & 1 & 5 & 4 & 3 \\
\hline & \multirow{2}{*}{$\begin{array}{l}\text { Quem quer se matar mesmo, não fica } \\
\text { "tentando" se matar }\end{array}$} & Pré & 1 & 1 & 1 & 1 & 1 \\
\hline & & Pós & 1 & 3 & 1 & 2 & 1 \\
\hline \multirow{6}{*}{$\begin{array}{l}\text { 4. Sem } \\
\text { categoria } \\
\text { específica }\end{array}$} & \multirow{2}{*}{$\begin{array}{l}\text { Geralmente, quem se mata tem alguma doença } \\
\text { mental }\end{array}$} & Pré & 5 & 1 & 4 & 3 & 4 \\
\hline & & Pós & 1 & 3 & 5 & 3 & 4 \\
\hline & \multirow[t]{2}{*}{$\begin{array}{l}\text { É preciso ter certa dose de coragem para se } \\
\text { matar }\end{array}$} & Pré & 4 & 4 & 1 & 3 & 3 \\
\hline & & Pós & 3 & 4 & 2 & 3 & 2 \\
\hline & \multirow{2}{*}{$\begin{array}{l}\text { Uma pessoa dificilmente se mata sem que } \\
\text { tenha um forte motivo para isso }\end{array}$} & Pré & 2 & 4 & 4 & 3 & 5 \\
\hline & & Pós & 1 & 4 & 1 & 3 & 2 \\
\hline
\end{tabular}




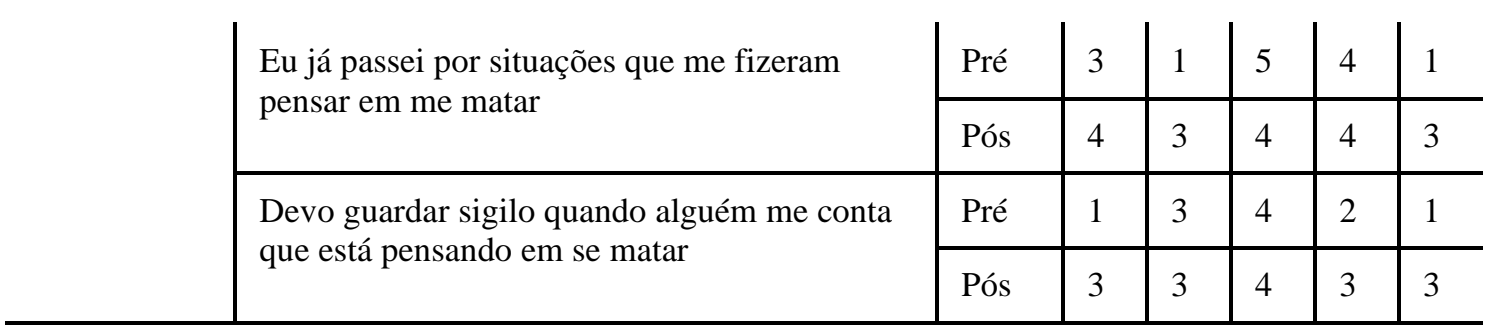

Fonte: Prado (2019a)

Em relação à primeira categoria, intitulada Capacidade profissional, pode-se inferir de cada item uma subcategoria para análise: posvenção, identificação de risco, manejo, segurança no manejo e encaminhamento. Os participantes apontaram melhora no manejo e no encaminhamento para a rede de saúde local, mas apresentaram índices menores na autoavaliação da capacidade profissional para posvenção (tema que não é abordado no material), na capacidade para identificar riscos e na segurança para lidar com estudantes em risco.

Na categoria Direito ao suicídio, houve uma diminuição na percepção de que a conversa pode prevenir o suicídio e também acerca da possibilidade de interferir na decisão da pessoa em risco. Este resultado, ao mesmo tempo que gera uma preocupação sobre a aprendizagem dos participantes em relação ao conteúdo apresentado, pode indicar uma melhor compreensão deles sobre a complexidade do comportamento suicida, no sentido de que apenas a conversa não seria suficiente para a prevenção e que outros encaminhamentos além deste seriam necessários. Foi observada outra ambiguidade nesta categoria no que refere ao aumento na percepção sobre o direito individual ao suicídio e também quanto ao item que afirma que "A vida é um dom de Deus, e só ele a pode tirar". Tendo em vista que a religiosidade aparece no material como possível fator de proteção, tendo sido citada na ação de capacitação, considera-se que pode ter havido alguma interferência nesse aspecto.

A categoria Sentimentos em relação à pessoa refere-se a que tipo de afeto a pessoa em risco desperta no profissional da educação e foi a categoria na qual os dados apareceram de forma mais dissonante em relação ao material apresentado, em 3 (três) itens que são relacionados à ameaça de suicídio e à disponibilidade para envolver-se com pessoas em risco. Destaca-se neste aspecto o sentimento de impotência diante de uma pessoa que quer se matar, que diminuiu em três participantes $(A, B, C)$, aumentou em um (E) e se manteve estável em outro (D). O receio de perguntar sobre a ideação suicida mudou de 5 para 1 para o participante $\mathrm{C}$, mas aumentou em 1 ponto para os participantes A e E. Novamente, a complexidade do comportamento suicida se evidencia na diferente 
percepção dos profissionais a respeito do que ouviram e de seus sentimentos em relação à pessoa em risco de suicídio.

A última categoria apresentou diferentes perspectivas em relação à doença mental. Houve aumento na percepção sobre guardar sigilo em relação à ideação - resultado inesperado em relação ao que foi apresentado na capacitação. Também mudaram as respostas sobre a própria ideação, que podem indicar alteração na autopercepção ou na disponibilidade/abertura para falar sobre os próprios sentimentos.

No que se refere ao padrão de respostas dos participantes, ressalta-se que o participante A apontou percepção de menor capacidade profissional e aumento no receio de perguntar sobre a ideação. Em relação ao direito ao suicídio, apresentou aumento neste item e também naquele que trata sobre a vidar ser um dom de Deus. Na aplicação do questionário após a capacitação, alterou completamente a resposta em relação ao fato de a doença mental ser condição para o suicídio.

Já o participante B apontou manutenção ou diminuição na categoria Capacidade profissional, embora tenha compreendido o encaminhamento para a rede. Houve alterações significativas no que se refere ao direito ao suicídio, no sentido de aprimorar a compreensão sobre esse aspecto, bem como em relação à categoria Sentimentos. C apresentou percepção de melhora na capacidade profissional e diminuição no sentimento de impotência diante de uma pessoa em risco de suicídio. D manteve uma constância de "sem opinião formada/indiferente" na maioria dos itens tanto antes quanto depois da aplicação nas categorias Capacidade profissional, Direito ao suicídio e Sem categoria específica; a exceção foi observada apenas na categoria Sentimentos. Por fim, E apresentou percepção na melhora na capacidade profissional de uma forma geral, mas os sentimentos relacionados à impotência diante de alguém que quer se matar aumentaram.

Em relação à pergunta aberta apresentada ao final do questionário e que pedia ao participante que apresentasse o que entendia por comportamento suicida, o Quadro 1 apresenta na íntegra as respostas dos participantes, que já tinham, em sua maioria, previamente uma noção sobre o fenômeno. $\mathrm{O}$ participante $\mathrm{B}$, que apontou não ter conhecimento, desenvolveu posteriormente uma resposta de acordo com o conteúdo apresentado. O participante E não respondeu na pós aplicação. 
Quadro 1: Descrição de comportamento suicida pelos participantes da aplicação

\begin{tabular}{|c|c|c|}
\hline & Apresente o que você entende por "comportamen & suicida": \\
\hline Participante & Pré & Pós \\
\hline A & $\begin{array}{l}\text { Auto mutilação, atitudes que desafiam a segurança } \\
\text { física e psíquica }\end{array}$ & $\begin{array}{l}\text { Pessoas com atitudes auto } \\
\text { destrutivas }\end{array}$ \\
\hline B & Não faço ideia. & $\begin{array}{l}\text { Sentimento de frustração dor e } \\
\text { sofrimento que apenas vê como } \\
\text { saída a morte }\end{array}$ \\
\hline $\mathbf{C}$ & $\begin{array}{l}\text { Quando a pessoa tenta uma ou mais vezes se matar, } \\
\text { não importando a motivação, "acho" que a auto- } \\
\text { lesão também pode estar ligada ou despertar um } \\
\text { comportamento suicida. "Sinto-me capaz de ajudar } \\
\text { uma pessoa..." um pouco, pois tenho empatia e boa } \\
\text { vontade, não formação. "Quando uma pessoa fala } \\
\text { de pôr fim à vida..." mas de uma forma empática, } \\
\text { sem menosprezar o sofrimento dela. "Eu já passei } \\
\text { por" é constante, mas acho que o tratamento } \\
\text { medicação+psiqui+psico me impede, e um medo do } \\
\text { pós-morte também rss. }\end{array}$ & $\begin{array}{l}\text { Ideia, planejamento e tentativa } \\
\text { de tirar a própria vida. }\end{array}$ \\
\hline $\mathbf{D}$ & $\begin{array}{l}\text { Tentativas de automutilação, tristeza profunda, } \\
\text { isolamento ou em alguns casos exposição extrema, } \\
\text { depressão. }\end{array}$ & $\begin{array}{l}\text { Entendo por comportamento } \\
\text { suicida alguém que tem } \\
\text { pensamentos suicidas e atitudes } \\
\text { (como por exemplo } \\
\text { automutilações). }\end{array}$ \\
\hline $\mathbf{E}$ & $\begin{array}{l}\text { comportamento suicida é um conjunto de sintomas } \\
\text { e atitudes que uma pessoa que corre risco de } \\
\text { cometer suicídio demonstra. }\end{array}$ & - \\
\hline
\end{tabular}

Fonte: Prado (2019a)

O questionário teve como objetivo avaliar se haveria mudança na forma como os participantes compreendem o comportamento suicida após terem recebido informações sobre o tema, durante a aplicação do produto educacional. Em alguns aspectos, observase que a ação atingiu seu objetivo, como no conhecimento do encaminhamento para a rede de saúde e no aumento de sentimentos mais positivos em relação à pessoa em risco de suicídio. Contudo, alguns itens sofreram mudança não esperada nas respostas, principalmente no que se refere ao direito ao suicídio e à segurança para lidar com estudantes em risco.

Algumas hipóteses sobre este resultado foram levantadas, mas, pelo tempo limite da pesquisa, não puderam ser testadas. A primeira delas foi a possibilidade de o método de avaliação escolhido não ser o mais adequado, uma vez que no questionário não é possível checar a compreensão do participante sobre a pergunta, nem verificar a interpretação da pesquisadora em relação às respostas. Nesse sentido, em relação à 
metodologia de aplicação escolhida (formato palestra), esta poderia ser testada em outro grupo, no formato roda de conversa, por exemplo, para que o feedback dos participantes fosse imediato.

Outra variável a ser considerada foi o tempo de aplicação do produto e a possibilidade de os participantes terem ficado com dúvidas que necessitariam de maior tempo para discussão. Reconhece-se que se trata de um tema complexo e que, como tal, demanda maior tempo e profundidade para se gerar mudança de atitude na identificação e na resposta ao risco de suicídio tanto no sentido afetivo quanto técnico - dado que foi, inclusive, apontado pelos participantes da palestra. Diante disso, uma sugestão para um trabalho futuro seria a reaplicação do material em formato que permita maior tempo de discussão, bem como maior aprofundamento no tema e nas situações cotidianas da escola. Poderia ser realizado, preferencialmente, com um grupo desconhecido pela autora, a fim de minimizar possível viés de resposta por parte dos participantes e também de análise por parte da pesquisadora.

\subsection{Avaliação do produto educacional pela população-alvo}

Em 24 de junho de 2019, foi enviado, por e-mail, o material para a avaliação dos 46 (quarenta e seis) profissionais do IFPR que demonstraram interesse na ocasião do levantamento de dados, e também aos 13 (treze) servidores do campus Curitiba que participaram da ação - os profissionais desse campus que já estavam na primeira lista foram retirados do segundo grupo.

Os profissionais puderam responder a avaliação até o dia 01 de julho de 2019. Diante do pouco retorno, o prazo foi prorrogado até o dia 05 de julho de 2019. Assim, do total de 59 (cinquenta e nove) profissionais que receberam o material para avaliação, 20 (vinte) responderam representando o corpo técnico e docente. Os cargos de Assistente em Administração, Assistente de Alunos e Docente não contemplados na primeira etapa de levantamento de dados foram incluídos na aplicação do produto no campus Curitiba.

Nesta segunda parte da amostra, o nível de escolaridade dos servidores foi, em sua maioria, de participantes com mestrado (14 profissionais). Os demais (6 [seis] servidores) tinham nível superior completo. Já em relação à formação dos servidores no âmbito da saúde mental, 15 (quinze) apontaram ter formação no tema. A última pergunta para a caracterização dos participantes foi em relação a já ter participado de alguma capacitação 
sobre prevenção do suicídio, para a qual 14 (quatorze) servidores responderam afirmativamente.

Isso posto, a seguir apresenta-se a avaliação dos profissionais sobre o material educativo produzido. $\mathrm{O}$ formulário de avaliação foi colocado em formato de afirmações em que o participante podia escolher um número de 1 a 5: 1 representando "discordo totalmente" e 5, "concordo completamente". O número 3 representava uma opinião indiferente. As respostas foram compiladas e organizadas graficamente para análise. Em termos quantitativos, considerando a média dos valores indicados pelos profissionais na avaliação do produto, de forma geral, o produto foi muito bem avaliado. $\mathrm{O}$ item com melhor avaliação foi a adequação da linguagem, com média 5, e o que menos atendeu às expectativas foi a aptidão dos profissionais para lidar com estudantes em risco, com média 4,15. Neste artigo, entretanto, serão apresentadas as respostas descritivas.

Inicialmente, em relação à compreensibilidade do conteúdo, conforme o objetivo do material, os profissionais apontaram quase unanimemente que ele atende a este item de avaliação na sua totalidade. Na avaliação, um participante apontou que "o texto está muito claro e bastante objetivo. As informações estão suficientes para um primeiro contato, ao mesmo tempo em que dão abertura e incentivo ao aprofundamento!”.

Já no que se refere à quantidade de material e, mais especificamente, se ele é suficiente para atender ao objetivo proposto, é possível observar que o material não atingiu completamente este item. Um dos participantes avaliou da seguinte maneira: "considerando o objetivo da cartilha, o conteúdo apresentado é suficiente optei pelo 3, pois ainda não tive a oportunidade de colocar o que foi apresentado em prática, e também nunca tinha tido antes um treinamento sobre o tema suicídio".

A utilidade do material para a realidade da prática profissional também foi avaliada pelos participantes como de relevância. Segue o excerto de uma das respostas: "primeiramente gostaria de elogiar o trabalho, a cartilha foi bem desenvolvida e aborda de forma clara o tema, com informações importantes e úteis. O conteúdo indica uma boa pesquisa prévia, sobre o qual se sustentam as informações apresentadas”.

Outro participante escreveu que

o material está bastante contextualizado, conciso com orientações claras e objetivas de como proceder nas diferentes situações que envolver a temática do suicídio. Traz elementos estatísticos e históricos que eu desconhecia. Layout limpo e atrativo à leitura. O material, com certeza, será de grande valia para nossa atuação como psicólogo escolar. 
Outro importante item avaliado foi a questão do uso adequado da linguagem na abordagem do assunto - até porque este é um aspecto que o material trata como ponto de atenção. Todos os participantes apontaram a adequação do material neste quesito. Alguns comentários apontaram para erros de digitação e de repetição de palavras, que foram corrigidos para a versão final do produto.

No que se refere ao uso da linguagem, foi solicitado aos participantes que avaliassem sua adequação em relação ao público-alvo do material educativo. Em relação a este ponto, observa-se o seguinte comentário de um participante, apontando que alguns pontos precisavam ser melhor explicados no que diz respeito à ideia de rede de apoio, formas de encaminhamento e vocabulário:

Só para contribuir: Quanto ao conteúdo achei que faltou explicar melhor como criar uma rede de apoio ao estudante (de profissionais? ou de colegas também?) e em relação à linguagem acho que uma ou outra palavra são do vocabulário do psicólogo, podendo não gerar compreensão de toda pessoa que acesse o material. E sobre saber encaminhar ainda fiquei com dúvidas quanto aos procedimentos formais/legais (preencher fichas ou relatórios, para quem enviar, em que ordem).

Diante disso, algumas alterações foram realizadas no texto, com o intuito de descrever melhor o que é uma rede de apoio e quais são os procedimentos de encaminhamento para a Rede de Atenção Psicossocial (RAPS), conforme exemplificado na Figura 2. 
Figura 2: Capítulo sobre a Rede de Atenção Psicossocial do produto educacional

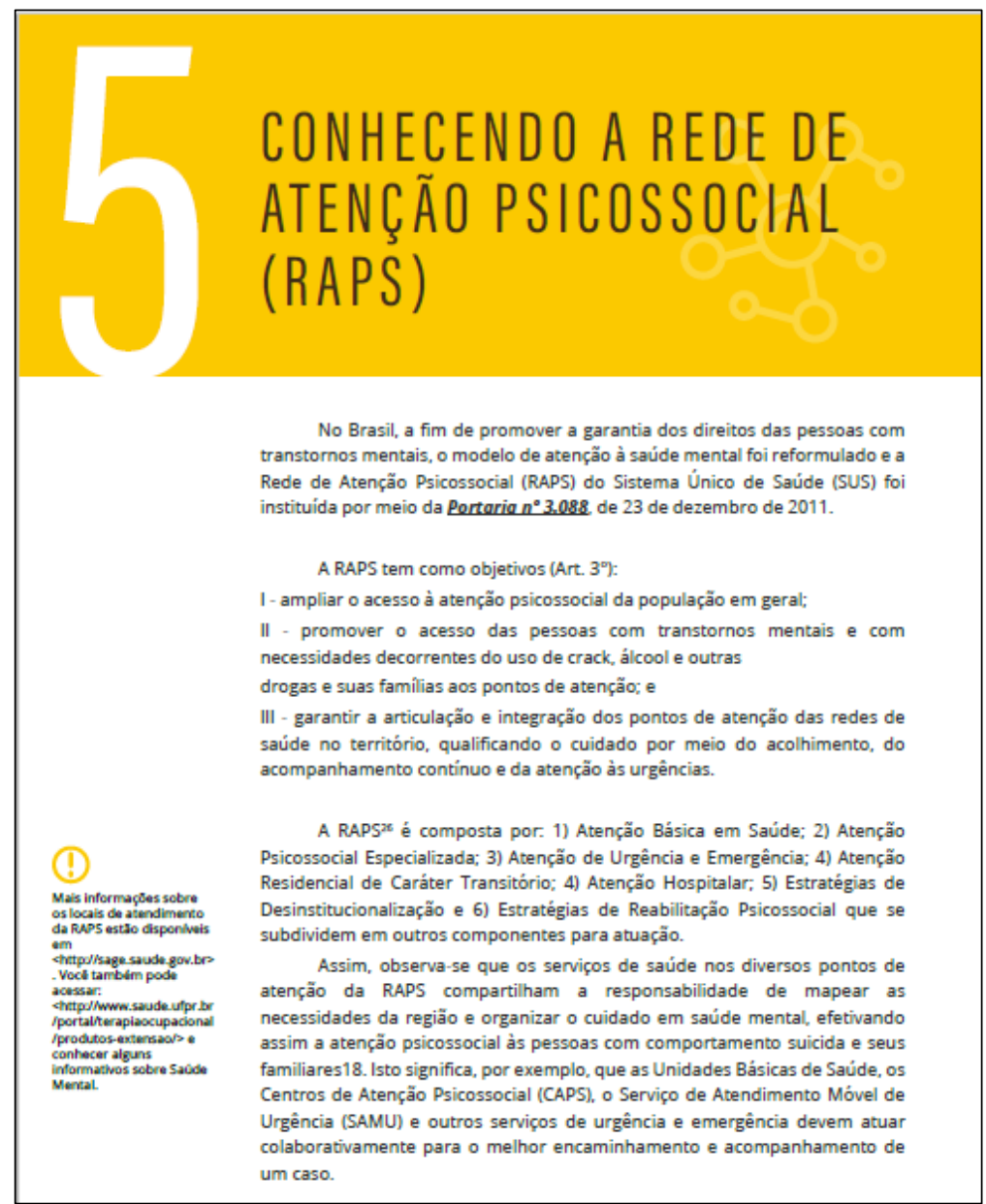

Fonte: Prado (2019b)

Sobre a utilidade das informações apresentadas para a prática profissional, os participantes majoritariamente apontaram a pertinência do material. Um dos participantes forneceu muitas sugestões sobre essa adequação, que foram amplamente consideradas na revisão do material. Outro profissional destacou a proposta do folder (Figura 3) e a possibilidade de ser utilizada em sua prática profissional:

gostei muito da proposta do folder informativo ao final do material, com um resumo das orientações principais. Facilita a conscientização de docentes e servidores e inclusive, serve para estudantes que vierem buscar informações de como ajudar seus amigos que estejam com ideação suicida. Parabéns pelo excelente trabalho! 
Figura 3: Folder informativo

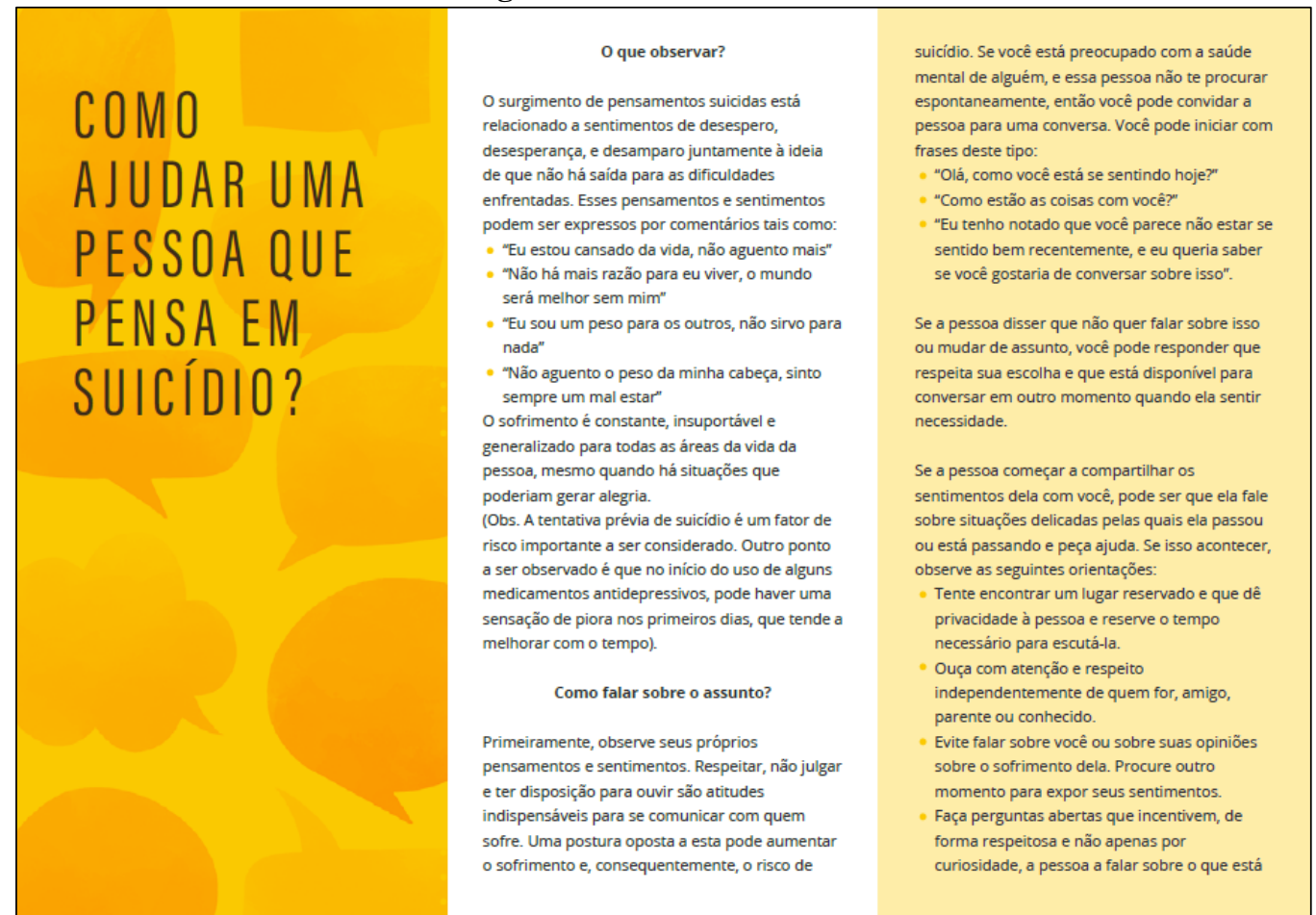

Fonte: Prado (2019b)

O design do material foi o item de avaliação que recebeu importantes sugestões na resposta descritiva. Um dos participantes apontou que "o design está bem bacana, mas seria melhor se houvesse mais imagens e ilustrações", e outro escreveu que "seria interessante incluir mais imagens, quem sabe conseguir desenvolver uma identidade visual iconográfica". Assim, a fim de facilitar a leitura e torná-la mais acessível, as sugestões foram encaminhadas ao profissional da área gráfica para revisão.

Para averiguar se o material atendeu às expectativas dos participantes que responderam ao questionário de levantamento de necessidades e informações sobre o tema, este item foi apresentado a eles. Observa-se que suas respostas se distribuíram principalmente entre "parcialmente" e "totalmente", ainda que se observe a indicação média em três participantes. Nenhum deles apresentou comentário específico sobre este item.

Em relação a recomendar o material a outras pessoas, os profissionais apontaram que o fariam e descreveram o produto como "Excelente material, com certeza será de grande valia para todos os educadores e educadoras".

O objetivo primário do material era fornecer informações cientificamente embasadas aos profissionais, de forma mais acessível e com uma linguagem mais apropriada ao contexto escolar. Considerando que uma das dificuldades identificadas na etapa de levantamento de dados foi a aptidão para realizar ações de prevenção do suicídio 
no ambiente escolar, uma das perguntas pretendeu avaliar o alcance do material neste aspecto. Assim, os profissionais foram questionados se se sentiam mais preparados para realizar ações de prevenção do suicídio com a leitura do material. As respostas apresentadas indicam que apenas parcialmente, e não houve comentários específicos sobre este item para que o material pudesse ser melhorado. É possível observar que este resultado é similar ao da aplicação do material no campus, o que corrobora com a complexidade do tema e com a necessidade de estratégias mais regulares de formação neste âmbito.

Nessa mesma linha, os profissionais foram também questionados sobre sentiremse mais preparados para lidar com estudantes com risco de suicídio com a leitura do material. Acredita-se que a descrição mais detalhada do fluxo de encaminhamento para a rede, sugerida por um participante, pôde contribuir um pouco mais para este item. Contudo, a não indicação mais detalhada por parte dos participantes sobre o que poderia ajudar para a aquisição desta aptidão inviabilizou alterações neste aspecto. Ademais, reconhece-se a limitação do material e que, embora ele contribua, pode não ser suficiente para este objetivo. Desse modo, possivelmente, uma formação sobre o tema poderia ser uma possibilidade de continuidade.

Finalmente, considerando que um dos objetivos da cartilha era disseminar informações sobre o funcionamento da RAPS, um item de análise foi o conhecimento sobre o encaminhamento para a rede. É possível perceber que as informações apresentadas ainda não estavam suficientes, o que também foi apresentado em uma das respostas descritivas. Assim, o conteúdo sobre este tópico foi ampliado e novas informações sobre a forma de encaminhamento foram acrescentadas para a versão final.

Para finalizar o tópico de avaliação sobre o produto educacional, segue uma parte da descrição feita por um dos profissionais que elucida bastante a razão e o objetivo da construção do material educacional:

\footnotetext{
Já vivenciei essa situação como mãe e como professora. Me senti responsável e ínfima em todas os momentos que vivenciei ligados a estes acontecimentos. Como professora vivenciei 2 suicídios (muito triste) e como mãe passe por um quase "suicídio" (sic). Mesmo trabalhando 20 anos como professora em uma instituição particular de ensino, nunca nos foi abordado tal assunto. Lembro que quando ficamos sabendo de um dos estudantes (13 anos), ficamos atordoados e não sabíamos (colaboradores da escola) o que fazer, como abordar o assunto com os estudantes, etc. Tristemente a escola optou pela omissão. Muito triste. Como mãe me senti pior ainda... Pois não conseguia ver o que estava embaixo do meu nariz e após saber sobre os fatos, me martirizava sempre tentando entender onde foi que errei. Gostaria de ter recebido esse material a muito tempo atrás. Acho importante a divulgação do mesmo.
} 
Observa-se que a avaliação qualitativa foi fundamental devido à possibilidade de expressar de forma mais autêntica a opinião dos profissionais. Para além das categorias elencadas pela pesquisadora, possibilitou elaborar uma versão final do material que fosse o mais próximo possível da realidade e das demandas mapeadas.

\section{Considerações finais}

O produto educacional "Vamos falar sobre suicídio? A prevenção no ambiente escolar" (PRADO, 2019b), resultado da pesquisa aplicada realizada no âmbito da Educação Profissional e Tecnológica, teve o objetivo de apresentar informações sobre o comportamento suicida e o manejo de situações de risco de suicídio na escola. É um material direcionado aos profissionais que atuam no ambiente escolar, abordando temas como alguns mitos sobre suicídio, fatores de risco e proteção, importância de uma linguagem adequada ao tratar do assunto, sinais de alerta em estudantes, avaliação de risco e encaminhamento para a Rede de Atenção Psicossocial, Setembro Amarelo, além de indicações de materiais extras para consulta. Ele pode ser acessado gratuitamente na plataforma EduCAPES ${ }^{5}$.

Seu caráter inovador reside na sua elaboração baseada nas demandas apontadas pelos profissionais da escola, na realidade escolar e em serviços de saúde brasileiros. Como limitação, pode-se apontar que foi elaborado no contexto da educação profissional e tecnológica da rede federal de ensino, de forma que uma ampliação contingente a outros contextos escolares e de outras faixas etárias é indicada.

Este artigo teve o objetivo de apresentar o processo de construção deste material, discutindo seu percurso e seus dados. Espera-se que este trabalho inspire outros de natureza semelhante, já que os casos de suicídio infanto-juvenil seguem crescendo consideravelmente no país, como apontado no início deste artigo.

\section{Referências}

BARDIN, L. Análise de Conteúdo. Tradução Luís Antero Reto, Augusto Pinheiro. 3 reimp. São Paulo: Edições 70, 2016.

BENINCASA, M.; REZENDE, M. M. Tristeza e suicídio entre adolescentes: fatores de risco e proteção. Bol. psicol, São Paulo, v. 56, n. 124, p. 93-110, jun. 2006. Disponível em: http://pepsic.bvsalud.org/scielo.php?script=sci_arttext\&pid=S000659432006000100007\&lng=pt\&nrm=iso. Acesso em: 20 maio. 2019

\footnotetext{
${ }^{5}$ Disponível em: http://educapes.capes.gov.br/handle/capes/553647
} 
BOTEGA, N. J. et al. Nursing personnel attitudes towards suicide: the development of a measure scale. Revista Brasileira de Psiquiatria, São Paulo, v. 27, n. 4, p. 315-318, dez. 2005.

BOTEGA, N. J. Crise Suicida: avaliação e manejo. Porto Alegre: Artmed, 2015.

BRASIL. Ministério da Educação. Lei no 11.892, de 29 de dezembro de 2008. Institui a Rede Federal de Educação Profissional, Científica e Tecnológica, cria os Institutos Federais de Educação, Ciência e Tecnologia, e dá outras providências. Brasília, DF, 2008. Disponível em: http://www.planalto.gov.br/ccivil_03/_Ato2007-2010/2008/Lei/L11892.htm. Acesso em: 02 set. 2017.

BRASIL. Ministério da Saúde. Setembro Amarelo: Ministério da Saúde lança Agenda Estratégica de Prevenção do Suicídio. Brasil, 2017a. Disponível em: http://portalarquivos.saude.gov.br/images/pdf/2017/setembro/21/Coletiva-suicidio-21-09.pdf Acesso em: 14 abr. 2021.

BRASIL. Ministério da Saúde. Secretaria de Vigilância em Saúde. Suicídio: saber, agir e prevenir. Boletim Epidemiológico, Brasília, v. 48, n. 30. 2017b. Disponível em: http://portalarquivos2.saude.gov.br/images/pdf/2017/setembro/21/2017-025-Perfilepidemiologico-das-tentativas-e-obitos-por-suicidio-no-Brasil-e-a-rede-de-atencao-a-saude.pdf. Acesso em: 25 fev. 2021.

BRASIL. Congresso Nacional. Lei no 13.819, de 26 de abril de 2019. Institui a Política Nacional de Prevenção da Automutilação e do Suicídio. Brasília, DF, 2019. Disponível em: http://www.in.gov.br/web/dou/-/lei-n\%C2\%BA-13.819-de-26-de-abril-de-2019-85673796. Acesso em: 08 maio. 2019.

CARDOSO, A. S.; CECCONELLO, A. M. Fatores de risco e proteção para o suicídio na adolescência: uma revisão de literatura. Revista Perspectiva: Ciência e Saúde, Osório, v. 4, n. 2, p. 101-117, dez. 2019. Disponível em:

http://sys.facos.edu.br/ojs/index.php/perspectiva/article/view/432. Acesso em: 16 abr. 2021.

CARVALHO, O. F.; LACERDA, G. Dualismo versus congruência: diálogo entre o novo modelo brasileiro para a formação profissional e o modelo didático ESC (Experiencial, Científico e Construtivista). In: MOLL, J. (org.). Educação profissional e tecnológica no Brasil contemporâneo: desafios, tensões e possibilidades. Porto Alegre: Artmed, 2010, p. 301312.

COORDENAÇÃO DE APERFEIÇOAMENTO DE PESSOAL DE NÍVEL SUPERIOR (CAPES). Diretoria de Avaliação. Documento de área 2016. Área de avaliação: Ensino. Coordenadora de área: Tania Cremonini de Araújo-Jorge. 2016. Disponível em: http://capes.gov.br/images/documentos/Documentos_de_area_2017/DOCUMENTO_AREA_E NSINO_24_MAIO.pdf. Acesso em: 13 ago. 2018.

CRESWELL, J. W. Projeto de pesquisa: métodos qualitativo, quantitativo e misto. 2. ed. Porto Alegre: Artmed, 2007.

GARCIA, G. Sobre Viver: como ajudar jovens e adolescentes a sair do caminho do suicídio. São Paulo: Benvirá, 2018.

HAWTON, K.; SAUNDERS, K. E. A.; O'CONNOR, R. C. Self-harm and suicide in adolescents. The Lancet, Londres, v. 379, n. 9834, p. 2373-2382, jun. 2012. Disponível em: https://www.sciencedirect.com/science/article/abs/pii/S0140673612603225.

Acesso em: 01 abr. 2021. 
MACHADO, M. F. S.; LEITE, C. K. S.; BANDO, D. H. Políticas Públicas de Prevenção do Suicídio no Brasil: uma revisão sistemática. Revista Gestão \& Políticas Públicas, São Paulo, v. 4, n. 2, p. 334-356, dez. 2014. Disponível em: http://www.revistas.usp.br/rgpp/article/view/114406. Acesso em: 15 out. 2018.

MAGRINI, D. F. M. Atitudes do pessoal de enfermagem que atuam em emergências diante do comportamento suicida e fatores associados. 2016. 83f. Dissertação (Mestrado em Ciências) - Escola de Enfermagem de Ribeirão Preto, Universidade de São Paulo, Ribeirão Preto, 2016.

NOSELLA, P. Trabalho e perspectivas de formação dos trabalhadores: para além da formação politécnica. Revista Brasileira de Educação, Campinas, v. 12, n. 34, p. 137-151, jan./abr. 2007.

ORGANIZAÇÃO MUNDIAL DA SAÚDE (OMS). Prevenção do suicídio: um manual para professores e educadores. Genebra: OMS, 2000. Disponível em: http://www.who.int/mental_health/prevention/suicide/en/suicideprev_educ_port.pdf. Acesso em: 10 out. 2017.

PEREIRA, A. S. et al. Fatores de risco e proteção para tentativa de suicídio na adultez emergente. Ciênc. saúde coletiva, Rio de Janeiro, v. 23, n. 11, p. 3767-3777, nov. 2018. Disponível em: https://www.scielo.br/j/csc/a/GnVdNw8QX4cMkQVdqSDR45R/?lang=pt. Acesso em: 20 mai. 2019.

PRADO, A. S. É possível falar sobre suicídio na escola? A construção de um material educativo a partir do contexto da educação profissional e tecnológica. 2019.191f. Dissertação (Mestrado em Educação Profissional e Tecnológica) - Instituto Federal do Paraná, Curitiba, 2019a.

PRADO, A. S. Vamos falar sobre o suicídio? A prevenção no ambiente escolar. Curitiba: Instituto Federal do Paraná. 2019b. Disponível em: http://educapes.capes.gov.br/handle/capes/553647. Acesso em: 01 ago. 2021.

RAMOS, M. N. Marcos conceituais do ensino médio integrado: proposta para discussão. Brasília, DF, 2008. Contribuição de Marise Ramos à reunião com a SEB e SETEC/MEC, realizada em Brasília, nos dias 27 e 28 de maio de 2008. Mimeografado. Disponível em: http://forumeja.org.br/go/sites/forumeja.org.br.go/files/concepcao_do_ensino_medio_integrado 5.pdf. Acesso em 03 ago. 2021

ROSA, N. M. da. et al. Mortalidade por suicídio no Estado do Paraná segundo meios utilizados: uma análise epidemiológica. Jornal Brasileiro de Psiquiatria, Rio de Janeiro, v. 66, n. 2, p. 73-82, abr./jun. 2017. Disponível em: https://doi.org/10.1590/0047-2085000000153. Acesso em: 16 abr. 2021.

SAVIANI, D. Trabalho e educação: fundamentos ontológicos e históricos. Revista Brasileira de Educação, Campinas, v. 12, n. 32, p. 52-180, jan./abr. 2007. Disponível em: http://www.scielo.br/pdf/rbedu/v12n34/a12v1234.pdf. Acesso em: 19 nov. 2017.

SCAVACINI, K. Suicide Survivors Support Services and Postvention Activities: The availability of services and an intervention plan in Brazil. 2011. 50f. Dissertação (Master Program in Public Health, Mental Health Promotion and Suicide Prevention) - Department of Public Health Sciences, Karolinska Institute, Suécia, 2011. 
SCAVACINI, K. O suicídio é um problema de todos: a consciência, a competência e o diálogo na prevenção e posvenção do suicídio. 2018. 271f. Tese (Doutorado em Psicologia) Instituto de Psicologia, Universidade de São Paulo, São Paulo, 2018.

SCAVACINI, K. O suicídio é um problema de todos: a consciência, a competência e o diálogo na prevenção e posvenção do suicídio. 2018. 271f. Tese (Doutorado em Psicologia) Instituto de Psicologia, Universidade de São Paulo, São Paulo, 2018.

SEVERINO, A. J. Metodologia do Trabalho Científico. 23. ed. rev. e atual. São Paulo: Cortez, 2007.

SOUSA, G. S. et al. Revisão de literatura sobre suicídio na infância. Ciênc. saúde coletiva, Rio de Janeiro, v. 22, n. 9, p. 3099-3110, set. 2017. Disponível em: https://www.scielo.br/pdf/csc/v22n9/1413-8123-csc-22-09-3099.pdf. Acesso em: 16 abr. 2021.

TEIXEIRA, C. M. F. S. A escola como espaço de prevenção ao suicídio de adolescentes - relato de experiência. Revista Inter Ação, v. 27, n. 1, p. 99-114, 2007. DOI: 10.5216/ia.v27i1.1509. Disponível em: https://www.revistas.ufg.br/interacao/article/view/1509. Acesso em: 3 ago. 2021.

WAISELFISZ, J. J. Mapa da violência 2014: os jovens do Brasil. Brasília: Secretaria-Geral da Presidência da República, 2014.

WORLD HEALTH ORGANIZATION (WHO). Preventing suicide: a global imperative. Genebra: WHO, 2014. Disponível em: https://apps.who.int/iris/bitstream/handle/10665/131056/9789241564779_eng.pdf?sequence=1. Acesso em: 16 abr. 2021.

Recebido em: 02 de fevereiro de 2021.

Aceito em: 14 de abril de 2021. 